\title{
Efficacy of adjunctive Garcinia mangostana Linn (mangosteen) pericarp for bipolar depression: study protocol for a proof-of-concept trial
}

Melanie M. Ashton, ${ }^{1,2,3}$ iD Michael Berk, ${ }^{1,2,4,5,6}$ Chee H. Ng, ${ }^{3}$ Malcolm Hopwood, ${ }^{2,7}$ Seetal Dodd, ${ }^{1,4,6}$ Alyna Turner, ${ }^{1,4,8}$ Ellie Brown, ${ }^{1,4}$ Felice N. Jacka, ${ }^{1,9,10}$ Susan M. Cotton, ${ }^{5,6}$ Jon-Paul Khoo, ${ }^{1,11}$ Mary Lou Chatterton, ${ }^{12}$ Bianca E. Kavanagh, ${ }^{1}$ Sarah E. Nadjidai, ${ }^{3}$ Samantha L. Lo Monaco, ${ }^{1,13}$ Brian H. Harvey, ${ }^{14,15}$ Jerome Sarris, ${ }^{3,16}$ Gin S. Malhi, ${ }^{17,18,19}$ Nathan L. Dowling, ${ }^{3}$ Olivia M. Dean ${ }^{1,2,4}$ iD

${ }^{1}$ Deakin University, Innovation in Mental and Physical Health and Clinical Treatment (IMPACT) Strategic Research Centre, School of Medicine, Barwon Health, Geelong, Australia. ${ }^{2}$ Florey Institute for Neuroscience and Mental Health, University of Melbourne, Parkville, Australia. ${ }^{3}$ Department of Psychiatry, The Melbourne Clinic, University of Melbourne, Richmond, Australia. ${ }^{4}$ Department of Psychiatry, Royal Melbourne Hospital, University of Melbourne, Parkville, Australia. ${ }^{5}$ Orygen, National Centre of Excellence in Youth Mental Health, Parkville, Australia. ${ }^{6}$ Centre of Youth Mental Health, University of Melbourne, Parkville, Australia. ${ }^{7}$ Department of Psychiatry, Albert Road Clinic, University of Melbourne, Melbourne, Australia. ${ }^{8}$ School of Medicine and Public Health, Faculty of Health and Medicine, University of Newcastle, Callaghan, Australia. ${ }^{9}$ Centre for Adolescent Health, Murdoch Children's Research Institute, Melbourne, Australia. ${ }^{10}$ Black Dog Institute, Sydney, Australia. ${ }^{11}$ Faculty of Medicine, University of Queensland, Brisbane, Australia. ${ }^{12}$ Centre for Population Health Research, Deakin Health Economics, Deakin University, Geelong, Australia. ${ }^{13}$ School of Psychology, Faculty of Health and Behavioural Sciences, University of Queensland, Brisbane, Australia. ${ }^{14}$ Center of Excellence for Pharmaceutical Sciences, School of Pharmacy, North-West University, Potchefstroom, South Africa. ${ }^{15}$ Medical Research Council Unit (MRC) Unit on Risk and Resilience, University of Cape Town, Cape Town, South Africa. ${ }^{16}$ NICM Health Research Institute, Western Sydney University, Sydney, Australia. ${ }^{17}$ Academic Department of Psychiatry, Northern Sydney Local Health District, St. Leonards, Australia. ${ }^{18}$ Department of Psychiatry, Northern Clinical School, Faculty of Medicine and Health, University of Sydney, Department of Psychiatry, Northern Clinical School, Faculty of Medicine and Health, University of Sydney, Australia. ${ }^{19}$ Clinical Assessment Diagnostic Evaluation (CADE) Clinic, Royal North Shore Hospital, St. Leonards, Australia. iD MMA https://orcid.org/0000-00016832-4157, iD OMD https://orcid.org/0000-0002-2776-3935

\begin{abstract}
Objective: Bipolar depression is characterized by neurobiological features including perturbed oxidative biology, reduction in antioxidant levels, and a concomitant rise in oxidative stress markers. Bipolar depression manifests systemic inflammation, mitochondrial dysfunction, and changes in brain growth factors. The depressive phase of the disorder is the most common and responds the least to conventional treatments. Garcinia mangostana Linn, commonly known as mangosteen, is a tropical fruit. The pericarp's properties may reduce oxidative stress and inflammation and improve neurogenesis, making mangosteen pericarp a promising add-on therapy for bipolar depression.

Methods: Participants will receive 24 weeks of either 1,000 mg mangosteen pericarp or placebo per day, in addition to their usual treatment. The primary outcome is change in severity of mood symptoms, measured using the Montgomery-Åsberg Depression Rating Scale (MADRS), over the treatment phase. Secondary outcomes include global psychopathology, quality of life, functioning, substance use, cognition, safety, biological data, and cost-effectiveness. A follow-up interview will be conducted 4 weeks post-treatment.

Conclusion: The findings of this study may have implications for improving treatment outcomes for those with bipolar disorder and may contribute to our understanding of the pathophysiology of bipolar depression.

Clinical trial registration: Australian and New Zealand Clinical Trial Registry, ACTRN12616000028404.
\end{abstract}

Keywords: Garcinia mangostana; bipolar disorder; treatment; clinical trial; depression

\section{Introduction}

Bipolar disorder $(\mathrm{BD})$ is often a highly debilitating illness that is characterized by manic and depressive phases. The depressive phase confers the greatest burden of

Correspondence: Olivia Dean, IMPACT Strategic Research Centre, P.O. Box 281, Geelong, 3220, Australia.

E-mail: o.dean@deakin.edu.au

Submitted Mar 28 2018, accepted Jul 03 2018, Epub Oct 112018. disease, and is associated with the highest risk of suicide. $^{1,2}$ People with BD often have suboptimal recovery with conventional treatments. ${ }^{3}$ The depressive phase is more refractory to current therapies, which are generally more efficacious in the manic phase. Thus, the unmet

How to cite this article: Ashton MM, Berk $\mathrm{M}, \mathrm{Ng} \mathrm{CH}$, Hopwood M, Dodd S, Turner A, et al. Efficacy of adjunctive Garcinia mangostana Linn (mangosteen) pericarp for bipolar depression: study protocol for a proof-of-concept trial. Braz J Psychiatry. 2019;41:245-253. http://dx.doi.org/10.1590/1516-4446-2018-0114 
clinical need is greater in bipolar depression. In this paper, we describe the methodology for a clinical trial of a novel therapy for bipolar depression.

$\mathrm{BD}$ is characterized by perturbed oxidative biology, systemic inflammation, and changes in neurotrophins and related markers of neuroprogression. ${ }^{4,5}$ Multiple studies have linked the pathophysiology of BD with inflammation and immune dysregulation. ${ }^{6}$ The primary non-enzymatic and enzymatic antioxidants in the brain - glutathione (GSH), GSH peroxidase, catalase, and superoxide dismutase have all been reported to be altered in $\mathrm{BD}^{5}$ In addition, there are consistent findings of increased markers of oxidative stress, the most robust being peroxidation of cellular lipids. ${ }^{7}$ Oxidative damage both to proteins (protein carbonylation) and to DNA has also been shown consistently in BD. ${ }^{7}$ Serum levels of brain-derived neurotrophic factor (BDNF) are reduced in patients with BD during manic and depressive episodes, and have been shown to correlate negatively with the severity of symptoms. ${ }^{8}$ Mood-stabilizing pharmacotherapies have some antioxidative, anti-apoptotic, and neuroprotective properties, but their effects are limited, as illustrated by alterations in oxidative biology that are still apparent following treatment. ${ }^{9,10}$ Critically, redox-active agents such as $\mathrm{N}$-acetylcysteine have putative antidepressant actions in BD. ${ }^{11}$ Similarly, the efficacy of other agents targeting these pathways, including celecoxib (an antiinflammatory agent), minocycline (which promotes redox homeostasis and has anti-inflammatory and neuroprotective actions), ${ }^{10}$ and methylene blue (which re-enables mitochondrial electron transport chain function) $)^{12,13}$ provide support for targeting these pathways. With research findings implicating oxidative stress, neuroinflammation, and markers of neuroprogression (apoptosis and reduced neurogenesis), there is a potential for identification of new therapeutic targets that may contribute to better treatment options for bipolar depression. ${ }^{4}$

Garcinia mangostana Linn, commonly known as mangosteen, is a tropical evergreen fruit grown mainly in Southeast Asia. The edible flesh of the fruit is covered by a thick rind, or pericarp, which is highly bioactive. ${ }^{14,15}$ The pericarp is highly resistant to infection and has antiinflammatory and antioxidant properties that protect the flesh and seed and allow the plant to reproduce successfully. Mangosteen pericarp has been shown to reduce levels of pro-inflammatory cytokines such as interleukin-6 and tumor necrosis factor- $\alpha$, suppress cyclooxygenase and nitric oxide synthase, and attenuate mitogen-activated protein kinase (MAPK) levels in vitro. ${ }^{16}$ These anti-inflammatory effects are thought to occur by inhibition of nuclear factor kappa B (NFKB). ${ }^{17}$ The antioxidative effects of mangosteen pericarp and its bioactive ingredients, mostly polyphenolic derivatives, are also well known. ${ }^{18}$ For example, mangosteen pericarp inhibits lipid peroxidation and GSH depletion, leading to reduced levels of oxidative stress markers (e.g., malondialdehyde), ${ }^{18}$ and potentially exerts neuroprotective effects by scavenging peroxides and peroxynitrite, preventing excitotoxicity-induced oxidative stress and inhibiting disruption of mitochondrial function. ${ }^{19}$ As outlined, this is congruent with neurobiological changes noted in BD.
Alterations in neurogenesis in BD have been described, ${ }^{4}$ and therapeutic agents (i.e., mood stabilizers) have been shown to affect these pathways. ${ }^{20}$ Mangosteen pericarp contains over 85 bioactive constituents, including $\alpha$ - and $\beta$-mangostin (with the former being present at the highest concentrations), xanthones, polyphenols, tannins, and epicatechins. ${ }^{14,15} \alpha$-Mangostin, a key compound derived from mangosteen, has been shown to upregulate extracellular signal-regulated kinases (ERK), MAPK, c-Myc/Max, Akt, and p53 cell signaling pathways. ${ }^{14}$ Downstream, these pathways affect cell proliferation, cell growth, survival, cell motility, protein synthesis, and transcription via two proteins that regulate cell death pathways, $\mathrm{Bcl}-2$ and p53. ${ }^{14}$ Lastly, mangosteen pericarp has been shown to affect levels of neurotransmitters and their receptors, including acetylcholine, acetylcholine esterase, and 5-hydroxytryptamine $2 \mathrm{~A}$ receptors, the latter a common target for some antipsychotics and antidepressants. ${ }^{15,21}$ A recent study in a translational animal model of depression (Flinders Sensitive Line rat) found marked antidepressant and pro-cognitive effects of mangosteen pericarp, as well as a reduction in hippocampal lipid peroxidation and correction of disordered regional brain monoamines. ${ }^{22}$ As the constituents of mangosteen pericarp also reduce oxidative stress and inflammation and improve neurogenesis, it appears to be a viable agent for exploration as an adjunctive therapy for bipolar depression. ${ }^{23}$

Significantly, a pilot study using $1,000 \mathrm{mg} /$ day mangosteen pericarp for 180 days in the adjunct to antipsychotic treatment of schizophrenia reported positive results. ${ }^{24}$ This double-blind placebo-controlled trial found a significant reduction in depression symptoms as measured on the Montgomery-Åsberg Depression Rating Scale (MADRS). These preclinical and pilot data, combined with the theoretical biological rationale, support the therapeutic potential of mangosteen pericarp in bipolar depression.

Within this context, the aim of this study is to investigate the efficacy of adjunctive mangosteen pericarp at a dose of $1,000 \mathrm{mg} / \mathrm{day}$ for the treatment of bipolar depression in a 24-week randomized, placebo-controlled design.

The primary outcome measure will be the change over time from baseline to end of the treatment period (primary endpoint, 24 weeks) in severity of mood symptoms, measured using the MADRS. Secondary outcomes include global psychopathology, quality of life (QoL), functioning, substance use, cost-efficacy, as well as safety and tolerability data. A follow-up interview will be conducted 4 weeks post-treatment discontinuation (i.e., at 28 weeks) to determine any changes in these outcomes following cessation of the trial agent.

Our primary hypothesis is that 24 weeks of adjunctive mangosteen pericarp treatment will be superior to placebo in reducing depression symptoms, as measured using the MADRS. Our secondary objectives/hypotheses are listed below:

1) A 24-week course of adjunctive mangosteen pericarp treatment will be superior to placebo for reducing symptom severity of bipolar illness, measured using validated scales (Clinical Global Improvement for Bipolar 
Disorder [CGI-BP], Hamilton Anxiety Rating Scale [HAM-A], Bipolar Depression Rating Scale [BDRS], Young Mania Rating Scale [YMRS], Patient Global Impression Scale [PGI]), and improving outcomes such as QoL (Quality of Life Enjoyment and Satisfaction Questionnaire - Short Form [Q-LES-Q-SF]), functioning (Social and Occupational Functioning Scale [SOFAS], Longitudinal Interval Follow-Up Evaluation - Range of Impaired Functioning Tool [LIFE-RIFT]), and cognition (digit span backwards and forwards tests, trail making task, and symbol digit task);

2) Participants in the mangosteen pericarp arm will exhibit better outcomes 4 weeks post-treatment discontinuation (week 28), based on change in symptom severity, QoL, and functioning scales (as during the treatment phase) than those in the placebo arm;

3) Participants in the mangosteen pericarp arm will have reduced oxidative stress (malondialdehyde) and inflammatory markers and improved markers of neuroprotection in peripheral (blood) samples compared to those in the placebo arm;

4) Clinical changes will correlate with discernible changes in oxidative stress markers (malondialdehyde) and inflammatory markers and improved markers of neuroprotection in peripheral (blood) samples; and

5) Adjunctive mangosteen pericarp treatment will be costeffective compared to placebo, from both health-sector and societal perspectives.

\section{Methods}

\section{Study design}

We plan to recruit a total of 150 participants (75 in the treatment arm; 75 in the placebo arm) from outpatient and inpatient settings in Australia. Participants attend a screening visit to ascertain suitability and are then randomized to receive either mangosteen pericarp extract or matched placebo, to be taken in addition to their treatment as usual. The monthly visit schedule over 24 weeks is not onerous and will aid recruitment and retention of participants. At the completion of the whole study, participants will be notified of the study arm to which they were assigned and will be given a summary of results. Participants have access to the Australian public healthcare system during and at completion of the trial for any necessary medical care. The study is being conducted according to the International Council for Harmonisation Good Clinical Practices (GCP) guidelines, with relevant human research ethics committee approval. The design of the study protocol is concordant with Standard Protocol Items: Recommendations for Intervention Trials (SPIRIT) guidelines. $^{25}$

\section{Randomization}

After the screening assessment has been completed and inclusion criteria satisfied, the participants are randomized. Allocation is by random assignment in a 1:1 ratio (active to placebo) using permutated block randomization.
Participants and researchers are blind to the treatment allocation (double-blind). Furthermore, all statistical analyses are completed blind (triple blinding). An independent researcher developed the computer-generated randomization plan. The manufacturer labels each study medication bottle with participant ID in accordance with randomization schedule. Blinding is maintained using an anonymous participant ID. The randomization plan is kept in an envelope in a locked filing cabinet for emergency unblinding by the trial pharmacist. Trial researchers allocate packs sequentially, and the investigational product is dispensed by an independent pharmacist. To explore expectancy effects, participants and research clinicians are asked at the week 24 visit if they believe the participant was taking the placebo or the mangosteen pericarp.

\section{Participants}

\section{Inclusion criteria}

For inclusion in the study, participants must be aged 18 or over, have the capacity to consent to the study and to follow the instructions and procedures, have a current treating physician, and meet criteria for a DSM $-5^{26}$ diagnosis of BD I or II or another specified bipolar and related disorder and current major depressive episode. They must score $\geqslant 20$ on the MADRS, indicating a moderate level of severity of current symptoms. Participants' pre-existing psychotropic therapy regimen needs to have been stable for 4 weeks prior to study entry. Finally, participants are required to have adequate English fluency, so as not to require an interpreter to provide informed consent. To ensure participants still meet eligibility criteria, the MADRS is re-administered if there is a delay of $>7$ days between screening and baseline interviews, or baseline interview and medication commencement.

\section{Exclusion criteria}

Participants are ineligible to enter the trial under the following conditions: 1) known or suspected clinically unstable systemic medical disorder; 2) pregnancy or breastfeeding; 3) contraindications or intolerance to mangosteen pericarp or any of the trial preparations; 4) and/or current enrollment in another clinical trial.

\section{Withdrawal criteria}

Participants will be withdrawn from the trial if they withdraw consent, become pregnant, or commence new electroconvulsive therapy treatment. Participants may also be withdrawn at the request of their treating physician or if they cease intake of the investigational product for greater than 7 consecutive days. If a participant is reporting an increase in their suicidal ideation, reaching five or more on the "suicidal ideation" item of the MADRS, the participant will be advised that they should contact their treating physician and that the trial team will do the same (further procedures are in place to address suicidal ideation and ensure participant safety). Withdrawal due to suicidal ideation is at the discretion of the research team, the participant, or at the request of the treating physician. 
Withdrawal due to adverse events is similarly at the discretion of the participant, research, or treating team. Changes to existing treatment regimens (pharmacoor psychological) will be accepted during the course of the trial.

\section{Investigational product}

\section{Mangosteen pericarp}

Mangosteen pericarp extract $(1,000 \mathrm{mg} /$ day, given as two $500 \mathrm{mg}$ capsules once a day) is the active intervention of this study. The raw powdered product is provided by VitalXan, Australia. This dosage is in keeping with a pilot study where the extract was well tolerated by participants. ${ }^{24}$

\section{Extraction from whole fruit}

Investigational product for the study was provided by a commercial supplier. The mangosteen pericarp extraction process was as follows: ripe mangosteen whole fruit is selected for quality, washed, and weighed. The mangosteen is then cut and the fruit pulp is separated from the rind. The inner rind, only, is extracted by water at $80^{\circ} \mathrm{C}$ for 2-3 hours, partially evaporated, and sterilized. The concentrated solution undergoes a spray-drying process which yields a powder extract; this is then analyzed for contaminants such as Escherichia coli, Salmonella, and Clostridium before packaging. Quality assurance is performed by the National Measurement Institute to detect impurities (agricultural chemicals). Finally, highperformance liquid chromatography is conducted by the Center for Phytochemistry and Pharmacology at Southern Cross University to assess concentration of $\alpha$-mangostin, the active ingredient, in the extract.

\section{Placebo}

Placebo capsules are made from starch. Placebos are produced by the same manufacturer at the same time as the investigational product and are matched in size and appearance.

\section{Adherence and dispensation}

Participants are asked to return all medication bottles with any unused capsules to check for adherence to investigational product intake.

Medication is dispensed to participants on a 4-weekly basis (baseline and weeks 4, 8, 12, 16, and 20). The first bottle is dispensed after the baseline visit has been completed and the participant has been randomized. Medication labeling conforms with GCP requirements. All investigational products are kept in a secure location under appropriate storage conditions.

Participants are instructed to take two capsules of the medication once per day with food, at the same time each day. Following completion of the trial, participants will be provided with information on how the investigational product can be purchased.

\section{Recruitment}

Trial researchers at each of the sites recruit participants from local mental health services. Community recruitment is conducted through online and print advertisements, radio advertising, and appearances; flyers placed in medical waiting rooms, pharmacies, and university campuses; and direct contact with other potential referral sources (private psychiatrists, support groups, general practitioners, and the disability support sector). Established procedures are employed to maximize recruitment and retention rates. ${ }^{27}$

\section{Data capture and management}

Trial data is collected during face-to-face interviews with participants. Trial researchers are trained in the outcome measures, and inter-rater reliability assessments are conducted within and across sites. To avoid dataentry and transcription errors, the trial will use automated electronic data entry via the Research Electronic Data Capture (REDCap) system, ${ }^{28}$ a metadata-driven internet browser-based system for data management. De-identified data will be stored securely, and common techniques for reducing data entry error will be used, such as data entry pages being locked from changes and using dropdown options as opposed to radial buttons when inputting data into REDCap. To further ensure data quality, the primary outcome measure - MADRS - will be administered on paper and will be double-entered for all participants.

Participants visit the study site at baseline and weeks 4 , $8,12,16,20,24$ (end of treatment), and 28 (4 weeks posttreatment discontinuation), at which time the battery of validated outcome measures is administered by research staff (see Table 1 for timeline and outcome measures). Additionally, participants are asked about their smoking, alcohol and substance use, and details on any medications they are taking. Height, weight, general demographics, and general and family psychiatric history are also captured at the baseline visit, with weight measured again at the week 24 visit. The study visit schedule has been designed to reflect previous successful trials by the authors. ${ }^{24,29}$ To aid retention, participants will be offered reimbursement for travel expenses up to $\$ 20$ per visit, once enrolled.

\section{Outcome measures}

\section{Efficacy measures}

MADRS (the primary outcome measure), ${ }^{30}$ BDRS, ${ }^{31}$ HAM-A, ${ }^{32}$ YMRS, ${ }^{33}$ CGI-BP (Severity and Improvement), ${ }^{34}$ and PGI (self-report). ${ }^{35}$

Functioning and QoL measures

SOFAS, ${ }^{36}$ LIFE-RIFT, ${ }^{37}$ and Q-LES-Q-SF (self-report). ${ }^{38}$

Health economics measures

Assessment of the Quality of Life Instrument 4D (AQoL$4 \mathrm{D})^{39}$ and a Resource use Questionnaire (RUQ), developed and used in prior economic evaluations by author MLC, 
Table 1 Study timeline and measurements

\begin{tabular}{|c|c|c|c|c|c|c|c|c|}
\hline Visit & $\begin{array}{c}1 \\
\text { Baseline/ } \\
\text { screening* }\end{array}$ & $\begin{array}{c}2 \\
\text { Interim } \\
\text { assessment }\end{array}$ & $\begin{array}{c}3 \\
\text { Interim } \\
\text { assessment }\end{array}$ & $\begin{array}{c}4 \\
\text { Interim } \\
\text { assessment }\end{array}$ & $\begin{array}{c}5 \\
\text { Interim } \\
\text { assessment }\end{array}$ & $\begin{array}{c}6 \\
\text { Interim } \\
\text { assessment }\end{array}$ & $\begin{array}{c}7 \\
\text { Primary } \\
\text { endpoint }\end{array}$ & $\begin{array}{l}8 \text { Post- } \\
\text { discontinuation } \\
\text { follow-up }\end{array}$ \\
\hline Week & 0 & 4 & 8 & 12 & 16 & 20 & 24 & 28 \\
\hline \multicolumn{9}{|l|}{$\begin{array}{l}\text { Screening and } \\
\text { consent }\end{array}$} \\
\hline Informed consent & $\mathrm{x}$ & & & & & & & \\
\hline Inclusion/ & $\mathrm{x}$ & & & & & & & \\
\hline \multicolumn{9}{|l|}{ exclusion criteria } \\
\hline Demographics & $\mathrm{x}$ & & & & & & & \\
\hline Medical history & $\mathrm{x}$ & & & & & & & \\
\hline $\begin{array}{l}\text { Psychiatric and } \\
\text { family history }\end{array}$ & $x$ & & & & & & & \\
\hline $\begin{array}{l}\text { Concomitant } \\
\text { medication }\end{array}$ & $x$ & $x$ & $x$ & $x$ & $\mathrm{x}$ & $\mathrm{x}$ & $\mathrm{x}$ & $\mathrm{x}$ \\
\hline $\begin{array}{l}\text { Pregnancy test } \\
\text { (females only) }\end{array}$ & $x$ & & & & & & & \\
\hline SCID-5-RV & $x$ & & & & & & & \\
\hline \multicolumn{9}{|l|}{ Safety } \\
\hline Adverse events & $x$ & $x$ & $x$ & $x$ & $\mathrm{x}$ & $\mathrm{x}$ & $\mathrm{x}$ & $\mathrm{x}$ \\
\hline \multicolumn{9}{|l|}{ Efficacy } \\
\hline MADRS & $\mathrm{x}$ & $\mathrm{x}$ & $x$ & $\mathrm{x}$ & $x$ & $\mathrm{x}$ & $\mathrm{x}$ & $x$ \\
\hline BDRS & $\mathrm{x}$ & $x$ & $x$ & $x$ & $x$ & $\mathrm{x}$ & $x$ & $x$ \\
\hline YMRS & $\mathrm{x}$ & $x$ & $x$ & $x$ & $x$ & $\mathrm{x}$ & $x$ & $x$ \\
\hline HAM-A & $\mathrm{x}$ & $x$ & $\mathrm{x}$ & $\mathrm{x}$ & $x$ & $x$ & $x$ & $x$ \\
\hline CGI-BP-S & $x$ & $x$ & $x$ & $\mathrm{x}$ & $x$ & $x$ & $\mathrm{x}$ & $x$ \\
\hline CGI-BP-I & & $\mathrm{x}$ & $\mathrm{x}$ & $\mathrm{x}$ & $\mathrm{x}$ & $\mathrm{x}$ & $\mathrm{x}$ & $\mathrm{x}$ \\
\hline PGI & & $x$ & $\mathrm{x}$ & $x$ & $\mathrm{x}$ & $\mathrm{x}$ & $x$ & $\mathrm{x}$ \\
\hline \multicolumn{9}{|l|}{$\begin{array}{l}\text { Functioning and } \\
\text { quality of life }\end{array}$} \\
\hline Q-LES-Q & $\mathrm{x}$ & $x$ & $x$ & $\mathrm{x}$ & $x$ & $x$ & $x$ & $x$ \\
\hline SOFAS & $\mathrm{x}$ & $x$ & $x$ & $x$ & $x$ & $x$ & $x$ & $x$ \\
\hline LIFE-RIFT & $x$ & $x$ & $x$ & $x$ & $\mathrm{x}$ & $\mathrm{x}$ & $\mathrm{x}$ & $\mathrm{x}$ \\
\hline \multicolumn{9}{|l|}{ Health economics } \\
\hline AQOL-4D & $\mathrm{x}$ & & & $\mathrm{x}$ & & & $x$ & \\
\hline$R \cup Q$ & $x$ & & & $x$ & & & $x$ & \\
\hline \multicolumn{9}{|l|}{$\begin{array}{l}\text { Exploration of } \\
\text { biological correlates }\end{array}$} \\
\hline Blood sampling & $x$ & & & & & & $x$ & \\
\hline \multicolumn{9}{|l|}{$\begin{array}{l}\text { Other moderator } \\
\text { variables }\end{array}$} \\
\hline SAPAS & $\mathrm{x}$ & & & & & & & \\
\hline DQES version 2 & $x$ & & & & & & & \\
\hline \multicolumn{9}{|l|}{ Cognition } \\
\hline $\begin{array}{l}\text { Digit span } \\
\text { backwards task }\end{array}$ & $\mathrm{x}$ & & & & & & $\mathrm{x}$ & \\
\hline $\begin{array}{l}\text { Digit span } \\
\text { forwards task }\end{array}$ & $x$ & & & & & & $x$ & \\
\hline Trail making task & $\mathrm{x}$ & & & & & & $\mathrm{x}$ & \\
\hline Symbol Digit Task & $x$ & & & & & & $x$ & \\
\hline \multicolumn{9}{|l|}{ Other } \\
\hline Drug dispensation & $\mathrm{x}$ & $\mathrm{x}$ & $\mathrm{x}$ & $\mathrm{x}$ & $x$ & $\mathrm{x}$ & & \\
\hline
\end{tabular}

AQOL-4D = Assessment of Quality of Life Instrument 4D; BDRS = Bipolar Depression Rating Scale; CGI-BP-S = Clinical Global Improvement for Bipolar Disorder - Severity; CGI-BP-I = Clinical Global Improvement for Bipolar Disorder - Improvement; DQES = Dietary Questionnaire for Epidemiological Studies; HAM-A = Hamilton Anxiety Rating Scale; LIFE-RIFT = Longitudinal Interval Follow-Up Evaluation - Range of Impairment Functioning Tool; MADRS = Montgomery-Assberg Depression Rating Scale; PGI = Patient Global Impression; Q-LES-Q = Quality of Life Enjoyment and Satisfaction Questionnaire; RUQ = Resource Use Questionnaire; SAPAS = Standard Assessment of Personality Abbreviated Scale; SOFAS = Social and Occupational Functional Assessment Scale; YMRS = Young Mania Rating Scale.

* Baseline and screening interviews may be split to accommodate participant time.

${ }^{\dagger}$ If participant is not sexually active or the treating clinician feels it is not warranted, this is not compulsory. 
will be used to measure healthcare services utilization by participants during the course of the trial. The RUQ asks participants to provide information on hospitalizations, consultations with health care providers, and other related health services utilized. The RUQ also asks questions regarding lost paid and unpaid productivity, to be used in the economic analyses from the societal perspective.

\section{Investigation of clinical and biological correlations}

Blood samples will be collected at baseline and at the end of the treatment phase (week 24) to investigate correlations and mediator effects between any clinical improvement and biological effects. Concordant with the preclinical literature on the redox anti-inflammatory apoptotic and neurotrophic properties of mangosteen pericarp, ${ }^{14,16,18}$ we will measure markers of inflammation, oxidative stress, and neurogenesis (neurotrophic and apoptotic factors) in participants consenting to venepuncture. Techniques that will be utilized for these analyses will be dependent on cutting-edge technologies available to the completion of the trial. At the time of writing, ELISA and Bio-Plex ${ }^{\mathrm{TM}}$ techniques are planned to be employed at this stage.

\section{Other safety measures and variables}

\section{Other moderator variables}

Personality will be measured using the Standard Assessment of Personality - Abbreviated Scale (SAPAS) ${ }^{40}$ and diet quality with the Cancer Council Victoria Dietary Questionnaire for Epidemiological Studies (DQES), version $2,{ }^{41}$ both at baseline. Cognition is assessed at the baseline and week 24 visits by the digit span backwards and forwards tests, ${ }^{42}$ trail-making task, ${ }^{43-45}$ and Symbol Digit Task. ${ }^{46}$

\section{Adverse events}

At every visit, participants are asked open-ended questions about their experience of taking the investigational product, allowing them to discuss their symptoms, side effects, and any issues they would like to raise regarding the trial. Any adverse events are reviewed by the principal investigator. The study is being overseen by a Data Safety Monitoring Board, which will review adverse events. If there are any ongoing adverse events at the final week 28 visit, the researcher will contact the participant 7 days after the visit to follow up and determine the outcome of the event (e.g., event resolved or ongoing). Serious adverse events are reported according to GCP guidelines.

\section{Statistical analysis}

All analyses will be conducted in accordance with the International Conference on Harmonization E9 statistical principles, ${ }^{47}$ and are based on all randomized participants with at least one post-baseline observation (modified intention-to-treat analyses). ${ }^{47}$ The primary efficacy analysis will use a likelihood-based mixed-effects model, repeated-measures approach (MMRM) using the average treatment group differences for the primary outcome measure (MADRS total score), over the entire treatment period (up to week 24). The MMRM model includes the fixed, categorical effects of treatment, investigator, visit, and treatment-by-visit interaction, as well as the continuous, fixed covariates of baseline score and baseline score-by-visit interaction. Planned comparisons will be done with the MMRM models to determine betweengroup differences in changes of symptoms measured from baseline to week 24. Similar comparisons will also be made using MMRM to explore changes from baseline to the post-discontinuation visit (week 28) and between weeks 24 and 28. Fisher's exact p-value or mixed linear regression will also be employed, where appropriate. Nonparametric statistics will be used when assumptions for parametric methods are violated. Effect sizes will be calculated using Cohen's guidelines. ${ }^{48}$ All tests of treatment effects will be conducted using a two-sided alpha level of 0.05 and $95 \%$ confidence intervals $(95 \% \mathrm{Cl})$. We will check for imbalances across the treatment arms by summarizing baseline characteristics using descriptive statistics and will test for differences using the chi-square test for categorical variables or independent $t$ test for continuous variables. If there are any imbalances between the randomized groups that may have occurred by chance, we will consider adjusting for one or more predictors in our multivariable analysis to account for any imbalance. Pearson product-moment correlations will be used to examine the relationships between the change scores for symptoms and the change scores for biological markers in the two groups. Using Fisher's z transformation, we will test whether the correlations obtained for each group are statistically different in terms of strength.

The economic evaluation will be conducted as a cost consequence analysis (CCA). We will compare the difference in costs and multiple outcomes (QoL, MADRS score, or other clinical measures) between the mangosteen pericarp and placebo arms, using incremental costeffectiveness ratios (ICERs). ${ }^{49}$

We will apply standard Australian unit costs (i.e., Medicare Benefits Schedule) to the resource use units collected. An average Australian wage rate will be used to value lost work time, also referred to as the human capital approach. ${ }^{50}$ Costs will be presented in total for both the health sector and societal perspectives. Bootstrapping will be used to obtain confidence intervals for cost effectiveness ratios. Sensitivity analysis will be conducted to assess the results against variation in parameters such as utility weights and unit costs for healthcare services or wages.

\section{Sample size calculation}

We are aiming for a target sample size of 150 participants. For a two-tailed analysis with $\alpha=0.05, Z \alpha=1.96$ and with $\beta=0.2, Z \beta=0.8$, and $n=120$, the study should be powered at $80 \%$ to detect a true difference in MADRS scale score between the mangosteen pericarp and placebo groups if the effect size is Cohen's $d=0.362$ or greater. This is a conservative estimate, based on the results of pilot 
data. $^{24}$ However, in our previous trial of $\mathrm{N}$-acetylcysteine specifically investigating bipolar depression, ${ }^{29}$ effect sizes for depressive symptoms (BDRS, MADRS), clinical global impression of depressive severity (CGI BP-depression), and all functional measures have shown effects similar to or above the effect size for which the present sample has been calculated. In our previous trials, we typically had an attrition rate of $20 \%$ for participants with no postbaseline data (e.g., Dean et al. ${ }^{51}$ ). Therefore, although power calculations indicated 120 participants would be sufficient to detect between group differences, we plan to recruit 150 participants to account for attrition.

\section{Discussion}

Mangosteen pericarp may target key biological factors implicated in BD. It replenishes $\mathrm{GSH}$, reduces oxidative and inflammatory stress, impacts apoptosis, and enhances neurogenesis. Furthermore, positive preclinical data suggests that mangosteen pericarp may improve depressivelike behavior; this effect appears to be linked to the aforementioned biological factors. Data from pilot clinical trials in schizophrenia indicate benefits in affective domains following adjunctive mangosteen pericarp treatment. If the results of our study are positive, this treatment has the potential to significantly enhance treatment options for people with bipolar depression. As this is a supplement that is readily available and of low cost, worldwide roll-out would be rapid. The trial may also contribute to our understanding of the underlying pathophysiology of bipolar depression. These are compelling reasons to investigate the efficacy of mangosteen in a pilot study for the treatment of bipolar depression.

\section{Trial status}

Recruitment commenced in Melbourne in 2016, Geelong in 2017, and will begin in Brisbane in 2018. The study has recruited 52 participants to date. Recruitment will continue into 2019.

\section{Ethical approval and consent to participate}

The trial has received ethics approval from Barwon Health Human Research and Ethics Committee (BH HREC: 15124), the Melbourne Clinic Research Ethics Committee (TMC REC: 262), and Deakin University Human Research and Ethics Committee (DU HREC: 2015-087). Any modifications will first be submitted to all ethics committees and, once approved, the trial registry will be updated. All participants will give informed consent before enrollment. No study-specific procedures or investigations will be performed before the participant has provided informed consent. Participants can choose to give additional informed consent for participation in the trial with or without blood collection and/or for blood collection for the investigation of genetic markers and/or the option to store blood samples for up to 15 years for future investigations. The safety of all participants will be paramount, and the trial will be conducted in accordance with Australian Clinical Trial
Guidelines and the National Ethical Guidelines for Human Research.

\section{Consent for publication}

Not applicable.

\section{Availability of supporting data}

Not applicable.

\section{Competing interests}

Deakin University holds a patent on the use of mangosteen (G. mangostana Linn) pericarp in schizophrenia, on which $\mathrm{MB}$ is listed as a co-inventor. All other authors declare they have no competing interests.

\section{Acknowledgements}

The study is being sponsored by Barwon Health and has been funded by the National Health and Medical Research Council (NHMRC; APP1121510), Deakin University, Australasian Society for Bipolar and Depressive Disorders (ASBDD)/Lundbeck, and Australian Rotary Health/lan Parker Bipolar Research Fund. The sponsors and funding bodies have played no role in collection, analysis, interpretation of results, or writing of the protocol.

\section{Disclosure}

MMA has received grant/research support from Deakin University, Australasian Society for Bipolar Depressive Disorders, Lundbeck, Australian Rotary Health, Ian Parker Bipolar Research Fund, and Cooperative Research Centre for Mental Health. MB has received grant support from the National Institutes of Health (NIH), Simons Autism Foundation, Cancer Council of Victoria, Cooperative Research Centres Programme (CRC) for Mental Health, Stanley Medical Research Foundation, Medical Benefits Fund of Australia Limited (MBF), NHMRC, Beyond Blue, Geelong Medical Research Foundation, Bristol-Myers Squibb, Eli Lilly, GlaxoSmithKline, Organon, Novartis, Mayne Pharma, and Servier; has been a speaker for AstraZeneca, BristolMyers Squibb, Eli Lilly, GlaxoSmithKline, Janssen-Cilag, Lundbeck, Merck, Pfizer, Sanofi-Synthelabo, Servier, Solvay, and Wyeth, and served as a consultant to AstraZeneca, Bristol-Myers Squibb, Eli Lilly, GlaxoSmithKline, Janssen-Cilag, Lundbeck, and Servier; is a co-inventor on two provisional patents regarding the use of NAC and related compounds for psychiatric indications, assigned to the Mental Health Research Institute. CHN has served in the advisory boards of Servier, Janssen-Cilag, Wyeth, and Eli Lilly; has received research grant support from Wyeth and Lundbeck and speaker honoraria from Servier, Lundbeck, Bristol-Myers Squibb, Organon, Eli Lilly, GlaxoSmithKline, Janssen-Cilag, AstraZeneca, Wyeth, and Pfizer. $\mathrm{MH}$ has received grant support from the International Society of Stem Cell Research (ISSCR), Servier, the United States Department of Defense (US DOD), and Bionomics; has been a speaker 
for Janssen-Cilag, Lundbeck, and Servier; and has been a consultant for AstraZeneca, Eli Lilly, Janssen-Cilag, Lundbeck, and Servier. SD has received grant support from the Stanley Medical Research Institute, NHMRC, Beyond Blue, the Australian Rotary Health Research Fund (ARHRF), Simons Foundation, Geelong Medical Research Foundation, Foundation FondaMental, Eli Lilly, GlaxoSmithKline, Organon, Mayne Pharma, and Servier; has received speaker fees from Eli Lilly, advisory board fees from Eli Lilly and Novartis, and conference travel support from Servier. AT has received travel or grant support from the NHMRC, Deakin University, AMP Foundation, National Stroke Foundation, Hunter Medical Research Institute, Helen Macpherson Smith Trust, Schizophrenia Fellowship New South Wales, SMHR, the International Society for Affective Disorders (ISAD), and the University of Newcastle. FNJ has received grant/ research support from the Brain and Behaviour Research Institute, the NHMRC, the ARHRF, the Geelong Medical Research Foundation, the Ian Potter Foundation, Eli Lilly, Meat and Livestock Australia, Woolworths Limited, Fernwood Gyms, The Wilson Foundation, GMHBA, and the University of Melbourne; has received speaker honoraria from Sanofi-Synthelabo, Janssen-Cilag, Servier, Pfizer, Health Ed, Network Nutrition, Angelini Farmaceutica, Eli Lilly, and Metagenics; and is supported by an NHMRC Career Development Fellowship (2) (\#1108125). SMC has received grant support from the NHMRC, the Stanley Medical Research Institute, BeyondBlue, Movember, the University of Melbourne, Australian Catholic University, the ARHRF, and Mental Illness Research Fund (Victoria Department of Human Services). JPK has received research support, travel and educational support, consultancy payments, and/or presentation honoraria from Alkermes, AstraZeneca, Bionomics, Bristol-Myers Squibb, Eli Lilly, GlaxoSmithKline, Janssen, Lundbeck, Pfizer, Sanofi-Aventis, Servier, and Wyeth. MLC has received grant support from NHMRC, BeyondBlue, Deakin University, Barwon, Child, Youth \& Family, and Medibank Health Research Fund. BEK has received research support from Deakin University, the Australian Government Research Training Program Scholarship, and the ARHRF. BHH has participated in advisory boards and received honoraria from Servier and has received research funding from the National Research Foundation (South Africa; IFR170207222124), South African Medical Research Council, Servier, Lundbeck, and Deakin University. JS has received either presentation honoraria, travel support, clinical trial grants, book royalties, or independent consultancy payments from Integria Healthcare \& MediHerb, Pfizer, Scius Health, Key Pharmaceuticals, Taki Mai, Bioceuticals \& Blackmores, Soho-Flordis, Healthworld, HealthEd, HealthMasters, Elsevier, Chaminade University, ISAD, Complementary Medicines Australia, Terry White Chemists, Australia Nutrition and Sports (ANS), Society for Medicinal Plant and Natural Product Research, UBiome, Omega-3 Centre, the NHMRC, and CR Roper Fellowship. GSM has received grant or research support from NHMRC, the ARHRF, NSW Health, Ramsay Health, American Foundation for Suicide Prevention, Ramsay Research and Teaching Fund, Elsevier, AstraZeneca, and Servier; has been a speaker for AstraZeneca, Janssen-Cilag, Lundbeck, and Servier; and has been a consultant for AstraZeneca, Janssen-Cilag, Lundbeck, and Servier. OMD is a R.D. Wright Biomedical Research Fellow and has received grant support from the Brain and Behavior Foundation, Simons Autism Foundation, Stanley Medical Research Institute, Deakin University, Lilly, NHMRC, and ASBDD/Servier. The other authors report no conflicts of interest.

\section{References}

1 Judd LL, Akiskal HS, Schettler PJ, Endicott J, Maser J, Solomon DA, et al. The long-term natural history of the weekly symptomatic status of bipolar I disorder. Arch Gen Psychiatry. 2002;59:530-7.

2 Simpson SG, Jamison KR. The risk of suicide in patients with bipolar disorders. J Clin Psychiatry. 1999;60:53-6; discussion 75-6, 113-6.

3 Malhi GS, Bassett D, Boyce P, Bryant R, Fitzgerald PB, Fritz K, et al. Royal Australian and New Zealand college of psychiatrists clinical practice guidelines for mood disorders. Aust N Z J Psychiatry. 2015;49: 1087-206.

4 Berk M, Kapczinski F, Andreazza AC, Dean OM, Giorlando F, Maes $M$, et al. Pathways underlying neuroprogression in bipolar disorder: focus on inflammation, oxidative stress and neurotrophic factors. Neurosci Biobehav Rev. 2011;35:804-17.

$5 \mathrm{Ng} \mathrm{F}$, Berk M, Dean O, Bush Al. Oxidative stress in psychiatric disorders: evidence base and therapeutic implications. Int $\mathrm{J}$ Neuropsychopharmacol. 2008;11:851-76.

6 Berk M, Williams LJ, Jacka FN, O'Neil A, Pasco JA, Moylan S, et al. So depression is an inflammatory disease, but where does the inflammation come from? BMC Med. 2013;11:200.

7 Andreazza AC, Kauer-Sant'anna M, Frey BN, Bond DJ, Kapczinski F, Young LT, et al. Oxidative stress markers in bipolar disorder: a metaanalysis. J Affect Disord. 2008;111:135-44.

8 Fernandes BS, Gama CS, Cereser KM, Yatham LN, Fries GR, Colpo G, et al. Brain-derived neurotrophic factor as a state-marker of mood episodes in bipolar disorders: a systematic review and metaregression analysis. J Psychiatr Res. 2011;45:995-1004.

9 Shao L, Young LT, Wang JF. Chronic treatment with mood stabilizers lithium and valproate prevents excitotoxicity by inhibiting oxidative stress in rat cerebral cortical cells. Biol Psychiatry. 2005;58:879-84.

10 Data-Franco J, Singh A, Popovic D, Ashton M, Berk M, Vieta E, et al. Beyond the therapeutic shackles of the monoamines: new mechanisms in bipolar disorder biology. Prog Neuropsychopharmacol Biol Psychiatry. 2017;72:73-86.

11 Berk M, Malhi GS, Gray LJ, Dean OM. The promise of N-acetylcysteine in neuropsychiatry. Trends Pharmacol Sci. 2013;34:167-77.

12 Alda M, McKinnon M, Blagdon R, Garnham J, MacLellan S, O'Donovan C, et al. Methylene blue treatment for residual symptoms of bipolar disorder: randomised crossover study. $\mathrm{Br} \mathrm{J}$ Psychiatry. 2017;210:54-60.

13 Delport A, Harvey BH, Petzer A, Petzer JP. Methylene blue and its analogues as antidepressant compounds. Metab Brain Dis. 2017;32: 1357-82.

14 Gutierrez-Orozco F, Failla ML. Biological activities and bioavailability of mangosteen xanthones: a critical review of the current evidence. Nutrients. 2013;5:3163-83.

15 Chin YW, Kinghorn AD. Structural characterization, biological effects, and synthetic studies on xanthones from mangosteen (garcinia mangostana), a popular botanical dietary supplement. Mini Rev Org Chem. 2008;5:355-64.

16 Gutierrez-Orozco F, Chitchumroonchokchai C, Lesinski GB, Suksamrarn S, Failla ML. $\alpha$-mangostin: anti-inflammatory activity and metabolism by human cells. J Agric Food Chem. 2013;61:3891-900.

17 Nakatani K, Yamakuni T, Kondo N, Arakawa T, Oosawa K, Shimura $S$, et al. gamma-mangostin inhibits inhibitor-kappaB kinase activity and decreases lipopolysaccharide-induced cyclooxygenase-2 gene expression in C6 rat glioma cells. Mol Pharmacol. 2004;66:667-74.

18 Sánchez-Pérez Y, Morales-Bárcenas R, García-Cuellar CM, LópezMarure R, Calderon-Oliver M, Pedraza-Chaverri J, et al. The alpha-mangostin prevention on cisplatin-induced apoptotic death 
in LLC-PK1 cells is associated to an inhibition of ROS production and p53 induction. Chem Biol Interact. 2010;188:144-50.

19 Pedraza-Chaverri J, Reyes-Fermin LM, Nolasco-Amaya EG, OrozcoIbarra M, Medina-Campos ON, Gonzalez-Cuahutencos O, et al. ROS scavenging capacity and neuroprotective effect of alpha-mangostin against 3-nitropropionic acid in cerebellar granule neurons. Exp Toxicol Pathol. 2009;61:491-501.

20 Boeckeler K, Adley K, Xu X, Jenkins A, Jin T, Williams RS. The neuroprotective agent, valproic acid, regulates the mitogen-activated protein kinase pathway through modulation of protein kinase A signalling in dictyostelium discoideum. Eur J Cell Biol. 2006;85:1047-57.

21 Khaw KY, Choi SB, Tan SC, Wahab HA, Chan KL, Murugaiyah V. Prenylated xanthones from mangosteen as promising cholinesterase inhibitors and their molecular docking studies. Phytomedicine. 2014; 21:1303-9.

22 Oberholzer I, Möller M, Holland B, Dean OM, Berk M, Harvey BH. Garcinia mangostana Linn displays antidepressant-like and procognitive effects in a genetic animal model of depression: a biobehavioral study in the flinders sensitive line rat. Metab Brain Dis. 2018;33:467-80

23 Chairungsrilerd N, Furukawa K, Ohta T, Nozoe S, Ohizumi Y. Histaminergic and serotonergic receptor blocking substances from the medicinal plant garcinia mangostana. Planta Med. 1996;62:471-2.

24 Laupu W. The efficacy of garcinia mangostana L (mangosteen) pericarp as an adjunctive to second-generation antipsychotics for the treatment of schizophrenia: a double blind, randomised, placebocontrolled trial [dissertation].Townsville: James Cook University; 2014.

25 Chan AW, Tetzlaff JM, Altman DG, Laupacis A, Gøtzsche PC, Krleža-Jerić K, et al. Spirit 2013 statement: defining standard protocol items for clinical trials. Ann Intern Med. 2013;158:200-7.

26 American Psychiatric Association. Diagnostic and Statistical Manual of Mental Disorders, Fifth Edition (DSM-5). Arlington: American Psychiatric Publishing; 2013.

27 Dean OM, Turner A, Malhi GS, Ng C, Cotton SM, Dodd S, et al. Design and rationale of a 16-week adjunctive randomized placebocontrolled trial of mitochondrial agents for the treatment of bipolar depression. Rev Bras Psiquiatr. 2015;37:3-12.

28 Harris PA, Taylor R, Thielke R, Payne J, Gonzalez N, Conde JG. Research electronic data capture (REDCap) -- a metadata-driven methodology and workflow process for providing translational research informatics support. J Biomed Inform. 2009;42:377-81.

29 Berk M, Copolov DL, Dean O, Lu K, Jeavons S, Schapkaitz I, et al. $\mathrm{N}$-acetyl cysteine for depressive symptoms in bipolar disorder a double blind, randomized, placebo-controlled trial. Biol Psychiatry. 2008;64:468-75.

30 Montgomery SA, Asberg M. A new depression scale designed to be sensitive to change. Br J Psychiatry. 1979;134:382-9.

31 Berk M, Dodd S, Dean OM, Kohlmann K, Berk L, Malhi GS. The validity and internal structure of the Bipolar Depression Rating Scale: data from a clinical trial of $\mathrm{N}$-acetylcysteine as adjunctive therapy in bipolar disorder. Acta Neuropsychiatr. 2010;22:237-42.

32 Hamilton M. Development of a rating scale for primary depressive illness. Br J Soc Clin Psychol. 1967;6:278-96.

33 Young RC, Biggs JT, Xiegler VE, Meyer DA. A rating scale for mania: reliability, valididty and sensitivity. Br J Psychiatry. 1978;133:429-35.
34 Spearing MK, Post RM, Leverich GS, Brandt D, Nolen W. Modification of the Clinical Global Impressions (CGI) scale for use in bipolar illness (BP): the CGI-BP. Psychiatry Res. 1997;73:159-71.

35 Viktrup L, Hayes RP, Wang P, Shen W. Construct validation of patient global impression of severity (PGI-S) and improvement (PGI-I) questionnaires in the treatment of men with lower urinary tract symptoms secondary to benign prostatic hyperplasia. BMC Urol. 2012;12:30.

36 Morosini PL, Magliano L, Brambilla L, Ugolini S, Pioli R. Development, reliability and acceptability of a new version of the DSM-IV social and occupational functioning assessment scale (SOFAS) to assess routine social functioning. Acta Psychiatr Scand. 2000;101: 323-9.

37 Keller MB, Lavori PW, Friedman B, Nielsen E, Endicott J, McDonaldScott $P$, et al. The longitudinal interval follow-up evaluation. A comprehensive method for assessing outcome in prospective longitudinal studies. Arch Gen Psychiatry. 1987;44:540-8.

38 Endicott J, Nee J, Harrison W, Blumenthal R. Quality of life enjoyment and satisfaction questionnaire: a new measure. Psychopharmacol Bull. 1993;29:321-6.

39 Hawthorne G, Richardson J, Osborne R. The assessment of quality of life (AQD) instrument: a psychometric measure of health-related quality of life. Qual Life Res. 1999;8:209-24.

40 Moran P, Leese M, Lee T, Walters P, Thornicroft G, Mann A. Standardised assessment of personality - abbreviated scale (SAPAS): preliminary validation of a brief screen for personality disorder. $\mathrm{Br} \mathrm{J}$ Psychiatry. 2003;183:228-32.

41 Hodge A, Patterson AJ, Brown WJ, Ireland P, Giles G. The anti cancer council of Victoria FFQ: relative validity of nutrient intakes compared with weighed food records in young to middle-aged women in a study of iron supplementation. Aust N Z J Public Health. 2000;24: 576-83.

42 Wechsler D. Wechsler adult intelligence scale-Fourth Edition (WAISIV). San Antonio: Psychological Corporation; 2014.

43 Reitan RM. Validity of the trail making test as an indicator of organic brain damage. Percept Mot Skills. 1958;8:271-6.

44 Lezark M. Neuropsychological Assessment. 3 ed. New York: Oxford University; 1995.

45 Corrigan JD, Hinkeldey NS. Relationships between parts A and B of the trail making test. J Clin Psychol. 1987;43:402-9.

46 Smith A. Symbol digit modalities test (SDMT). Manual (revised). Los Angeles: Western Psychological Services; 1982.

47 Food Drug Administration (FDA). International conference on harmonisation: guidance on statistical principles for clinical trials $(\mathrm{ICH}-$ E9). Fed Regist. 1997;62:25692-709.

48 Cohen J. Statistical power analysis for the behavioral sciences. 2nd ed. Hillsdale: L. Erlbaum Associates; 1988.

49 Glick HA, Doshi JA, Sonnad SS, Polsky D. Economic evaluation in clinical trials.Oxfrord: Oxford University; 2014.

50 Drummond MF, Sculpher MJ, Claxton K, Stoddart GL, Torrance GW. Methods for the economic evaluation of health care programmes. Oxford: Oxford University; 2015.

51 Dean OM, Kanchanatawan B, Ashton M, Mohebbi M, $\mathrm{Ng} \mathrm{CH}$, Maes $\mathrm{M}$, et al. Adjunctive minocycline treatment for major depressive disorder: a proof of concept trial. Aust N Z J Psychiatry. 2017;51: 829-40. 